\title{
Targeting a Neutralizing Epitope of HIV Envelope Gp120 by Immune Complex Vaccine
}

Rajnish Kumar ${ }^{1}$, Maria Luisa Visciano ${ }^{1}$, Hualin $\mathrm{Li}^{1}$ and Catarina Hioe ${ }^{1,2 *}$

${ }^{1}$ New York University School of Medicine, Department of Pathology, New York, NY 10016, USA

${ }^{2}$ Veterans Affairs New York Harbor Healthcare System, Manhattan Campus, New York, NY 10010, USA

\begin{abstract}
There are formidable challenges in developing HIV vaccines that elicit potent neutralizing antibodies against a broad array of HIV-1 isolates. The key targets for these neutralizing antibodies are the viral envelope antigens gp120 and gp41. Although broadly reactive neutralizing epitopes on gp120 and gp41 have been mapped and studied extensively, these epitopes are poorly immunogenic. Indeed, various vaccine candidates tested in preclinical and clinical trials do not generate antibodies against these epitopes. Hence, novel immunogen designs to augment the immunogenicity of these neutralizing epitopes are wanted. In this review, a unique immunogen design strategy that exploits immune complexes of gp120 and selected anti-gp120 monoclonal antibodies (mAb) to elicit neutralizing antibodies against cross-reactive V3 epitopes is discussed. The ability of these complexes to stimulate neutralizing antibodies is dictated by fine specificity and affinity of mAbs used to form the complexes, indicating the contribution of Fab-mediated activity, rather than conventional Fc-mediated enhancement. Further improvement of V3 immunogenicity is attainable by forming immune complexes with gp120 mutants lacking site-specific N-linked glycans. The increased V3 immunogenicity on the mutated gp 120/mAb complexes correlates with enhancement of in vitro antibody recognition (antigenicity) and proteolytic resistance of $\mathrm{V} 3$ epitopes when presented on the complexes. These insights should provide guidelines for the development of more potent immunogens that target not only the prototypic V3 epitopes but also other broadly reactive epitopes on the HIV envelope.
\end{abstract}

\section{Introduction}

Efforts to develop an effective HIV vaccine have yielded disappointing results. The Vaxgen recombinant gp120 protein vaccines tested in two Phase 3 trials were unable to induce protective antibody (Ab) response $[1,2]$, while the T-cell inducing vaccine in the Phase 2b STEP and Phambili trials delivered no apparent protection [3]. The Phase 3 RV144 trial, which evaluated a prime/boost regimen of recombinant ALVAC-HIV and two recombinant gp120 proteins, produced more promising results and suggested protective effects of anti-gp120 immunity, although the protection efficacy was low and appeared transient [4]. Thus, novel strategies are needed to create more efficacious HIV vaccines that elicit both cellular and humoral immunity, and innovative immunogens that focus $\mathrm{Ab}$ responses toward virus-neutralizing epitopes will be critical components for effective $\mathrm{Ab}$ based vaccines against HIV. This article will review our research efforts in developing a unique immune-complex vaccine platform to induce neutralizing $\mathrm{Ab}$ response against $\mathrm{HIV}$.

\section{HIV Envelope (Env): The Elusive Target for Broadly Neutralizing Abs}

HIV Env gp120 and gp41 are the only viral antigens expressed on the surfaces of virions and infected cells $[5,6]$. The gp120 subunit binds to CD4 and the chemokine receptors CCR5 or CXCR4. The CD4-binding site (CD4bs) and the chemokine receptor binding site are conformational surfaces formed with discontinuous peptide segments from different gp120 regions. From the linear sequence of gp120, five variable regions, $\mathrm{V} 1$ to $\mathrm{V} 5$, and five relatively conserved regions, $\mathrm{C} 1$ to $\mathrm{C} 5$, can be traced (Figure 1). The gp41 subunit contains the fusion peptide, the trimerization domain, the transmembrane anchor, and the cytoplasmic tail. Although HIV Env is the desired target for neutralizing Abs, it displays astonishing agility in evading $\mathrm{Ab}$ neutralization. It is notorious for its genetic and antigenic variability, and its critical conserved epitopes are poorly immunogenic or inaccessible to Abs due to glycan and conformational masking [7-17]. During HIV infection, neutralizing $\mathrm{Ab}$ responses to HIV Env are generated, but they arise slowly over several months after the acute viremia peaks $[18,19]$. These initial neutralizing Abs are directed primarily to epitopes that readily mutate, resulting in rapid and successive emergence of escape variants. Broadly neutralizing Abs arises much later, after years of infection [20]. The reasons for the late emergence of broadly neutralizing Abs remain unclear, but several mechanisms have been postulated, including HIVinduced destruction of the lymphoid microenvironment for B cells during early stages of infection [21], requirement for repetitive continual antigen stimulations to drive $B$ cell maturation and hypermutations that generate high-affinity $\operatorname{IgG}$ with long CDR3 regions characteristic of many broadly neutralizing monoclonal Abs [22-24], and modulatory effects of the early generated anti-Env Abs in shaping the repertoire of the later $\mathrm{Ab}$ responses [25].

\section{Neutralizing Epitopes on HIV Env}

Conserved neutralizing Env epitopes have been identified based on their recognition by broadly reactive monoclonal Abs (mAbs) [5]. In the gp120 subunit, these epitopes are associated with the CD4-binding site, the chemokine-receptor binding site, which encompasses the V3 loop and the bridging sheet (CD4-induced, CD4i), and N-linked glycans decorating the surface of gp120. Recently, other conserved epitopes recognized by highly potent and cross reactive neutralizing

${ }^{*}$ Corresponding author: Dr. Catarina E. Hioe, VA Medical Center, 423 East $23^{\text {rd }}$ Street, Room 18-124N, New York, NY 10010, USA, Tel: 212-263-6769; Fax: 212 951-6321; E-mail: catarina.hioe@nyumc.org

Received February 14, 2012; Accepted March 05, 2012; Published March 09 2012

Citation: Kumar R, Visciano ML, Li H, Hioe C (2012) Targeting a Neutralizing Epitope of HIV Envelope Gp120 by Immune Complex Vaccine. J AIDS Clinic Res S8:002. doi:10.4172/2155-6113.S8-002

Copyright: ( 2012 Kumar R, et al. This is an open-access article distributed under the terms of the Creative Commons Attribution License, which permits unrestricted use, distribution, and reproduction in any medium, provided the original author and source are credited. 
A

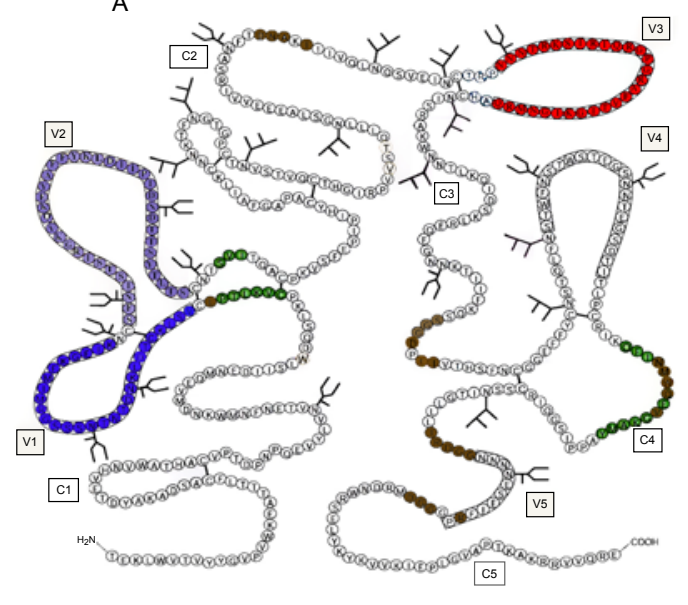

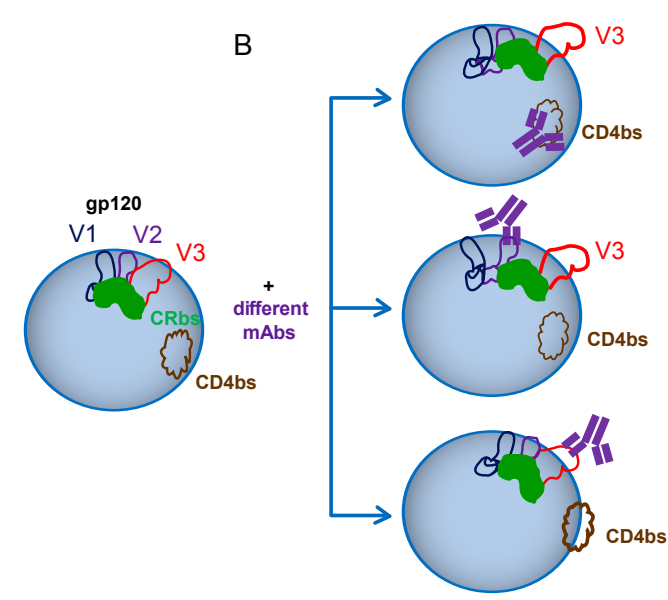

$\mathrm{C}$

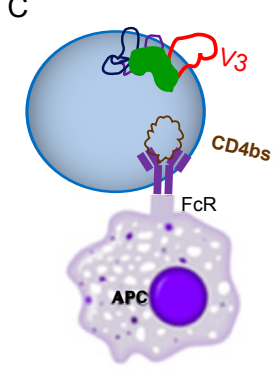

Figure 1: Immune complex vaccine strategy utilizes Fab- and Fc-mediated activities to stimulate robust Ab response against targeted epitopes on gp120

(A) This schematic diagram shows the linear sequence of gp120 where five relatively constant regions, C1 to C5, and five variable regions, V1 to V5, can be traced to $\mathrm{N}$ terminus to $\mathrm{C}$ terminus. The CD4-binding site (CD4bs) (highlighted in brown) and the chemokine receptor binding site (CRbs; green) are conformational surfaces formed with discontinuous segments from different gp120 regions (modified from ref [5]). (B) MAb binding to gp120 induces conformational changes that modulate the exposure and stability of different gp120 epitopes. This effect is Fab-mediated as it is dependent on the fine specificity of the mAb. Our immune complex vaccine strategy takes advantage of this modulatory activity to augment the immunogenicity of $\mathrm{V} 3$ and other neutralizing epitopes on gp120. For examples, immune complexes made of gp120 and anti-CD4 binding site mAbs enhance antigenicity and immunogenicity of V3 epitopes [40,55]. Similarly, gp120/anti-V2 mAb complexes display enhanced V3 reactivity [40]. Other gp120/mAb complexes have been identified that exhibit higher reactivity for epitopes in the CD4-binding site and the bridging sheet of the CRbs $[57,70]$. In support of this, conformational differences are observed in the crystallographic structures of gp 120 bound by CD4 and various mAbs $[22,52,71-73]$. However, the extent of structural alterations induced by these ligands remains unclear as no crystal structure of unliganded gp120 is available. (C) The Fc fragment of gp120/mAb complex interacts with Fc receptors on antigen-presenting cells to facilitate antigen uptake and processing for MHC class II presentation to helper T cells [42]. Hence, both Fab- and Fc-mediated activities play important roles in regulating the capacity of gp120/mAb complex vaccines to elicit effective immune responses against HIV.

mAbs VRC01-VRC03, PG9/16, CH01-CH04, PGT121-PGT145 [2630] was discovered. The epitopes recognized by mAbs VRC01-VRC03 are mapped to the CD4-binding site, while the other epitopes involve $\mathrm{N}$-linked glycans and conserved elements in the V1V2 and/or V3 loops. However, despite conservation of these epitopes among a large number of circulating HIV-1 isolates, Abs against these epitopes are produced only in a small fraction of HIV-1+ individuals [20,31,32]. For example, only $21 \%$ of the top $1-5 \%$ HIV + subjects with broadly neutralizing serum activities ("elite neutralizers") produce PG9/16-like Abs [31]. Immunization with vaccines bearing different gp120 epitopes also has failed to elicit broadly neutralizing Abs. These data indicate the poor immunogenicity of these epitopes as naturally presented on gp120. Hence, our lab has explored a strategy of utilizing immune complexes made of gp120 and selected anti-gp120 monoclonal Abs in order to improve immunogenicity of critical neutralizing epitopes such that Abs can be elicited against these epitopes by active immunization (Figure 1).

\section{Immune Complex Vaccines}

The capacity of immune complexes to augment antibody (Ab) responses in an antigen-specific manner is well documented [33]. Indeed, immune complexes have been tested as vaccines to augment Ab responses to hepatitis B surface antigen [34,35], infectious bursal disease virus [36], equine herpesvirus 1 [37], and porcine parvovirus $[37,38]$. A recent study also shows the utility of immune complexes, without any additional adjuvants, as intranasal vaccines against $F$. tularensis to induce protective mucosal immunity [39]. Similarly, we have demonstrated the ability of a gp120/mAb complex, but not uncomplexed gp120, administered in physiologic saline to elicit primary and secondary anti-gp120 antibody responses [40], indicating the function of Abs as a natural adjuvant. These adjuvant effects have been attributed, for the most part, to activities of the Fc fragment [41]. The interaction of immune complexes with Fc receptors on antigenpresenting cells facilitates antigen uptake, processing and presentation to augment CD4 $\mathrm{T}$ cell responses [42]. Additionally, immune complexes may be captured by and retained in follicular dendritic cells in the lymphoid follicles, which effectively increase the antigen concentration and half-life, leading to enhanced $\mathrm{B}$ cell activation and $\mathrm{Ab}$ production [33].

In addition to $\mathrm{Fc}$, Fab activity also contributes to the immune complex capacity to modulate $\mathrm{Ab}$ responses. Upon binding to its antigen, $\mathrm{Ab}$ can alter the stability and conformation of the antigen, while exposing or shielding specific epitopes [43]. Previous studies with model antigens such as dinitrophenylated keyhole limpet hemocyanin (DNP-KLH), gamma globulin, and albumin showed that immunization with immune complexes results in quantitatively and qualitatively different $\mathrm{Ab}$ responses than with antigens alone [33]. Immunization with Streptococcus mutans adhesin P1 coupled with an anti-P1 mAb elicited Abs of different specificities from immunization with the P1 antigen alone or with the P1 antigen coated with other mAbs $[44,45]$. Similarly, differences in the quality of immune responses were reported after immunization with hepatitis B surface antigen (HBsAg) protein subunits S and PreS2 bound by different mAbs [46] and HIV-1 gp120 antigen in complex with soluble CD4 or anti-V3 mAb as compared to unbound gp120 [47]. Conversely, the Fab fragment on immune complexes has been implicated in epitope masking that prevents $\mathrm{B}$ cell recognition, resulting in suppression of immune responses. One well-studied example is anti-Rhesus D IgG given to Rhesus-negative women during pregnancy or after delivery of a Rhesus-positive baby to block active immune response against Rhesus $\mathrm{D}$ and prevent hemolytic 
disease by the maternal IgG [48]. Experimental results in the murine model show that the levels of suppression correlate with IgG affinity; furthermore, suppressive activity occurs without affecting $\mathrm{T}$ cell priming and does not require $\mathrm{Fc} \gamma \mathrm{Rs}[49,50]$, indicating that anti-Rhesus D IgG activity is most likely due to masking of $\mathrm{Ab}$ epitopes. Nevertheless, in humans, the engagement of the inhibitory Fc $\gamma$ RIIB receptor may also contribute to the suppression of the anti-Rhesus D response. Thus, immune complexes via their Fab fragments can enhance or suppress $\mathrm{Ab}$ responses in a highly epitope- specific fashion. In our lab, we take advantage of this special property as a vaccine strategy to focus and augment the $\mathrm{Ab}$ responses toward the desired neutralizing $\mathrm{Ab}$ epitopes on HIV gp120.

\section{gp120 Structural Alterations by Abs}

HIV gp120 has an exceptionally dynamic structure. Its flexible elements include not only the highly mobile and variable loops, but also the inner and outer domains of gp120 core that are capable of adopting fluctuating conformations which shift toward and away from the formation of the Phe 43 pocket in the CD4-binding site and that of the bridging sheet in the chemokine receptor binding site $[17,51,52]$. Upon CD4 binding, gp120 undergoes extensive structural changes that lock both inner and outer domains of gp120 into a more rigid structure, creating and stabilizing the CD4-binding pocket and the chemokine receptor binding site $[17,53]$. This is consistent with the thermodynamic analyses showing the unusually large negative changes of enthalpy and entropy in gp120 triggered by CD4 binding, with refolding and reordering of as many as 65 amino acid residues during the interaction of gp120 with CD4 [17,51].

MAb binding to gp120 also triggers substantial changes and stabilizes the gp120 structure, albeit at conformations distinct from that induced by CD4. For example, comparing the CD4-bound gp120 vs. mAb b12-bound gp120 structures shows that although CD4 and $\mathrm{mAb}$ b12 bind to overlapping surfaces on gp120, unlike CD4, mAb b12 induces and stabilizes a gp120 conformation that does not allow gp120 interaction with the chemokine receptor. By contrast, mAb A32 exposes and stabilizes the bridging sheet of the chemokine receptor binding site that contains the so-called CD4-induced epitopes [54]. Consistent with these findings, our studies show that the binding of different mAbs with gp120 induces antigenic alterations at sites outside those directly bound by the $\mathrm{mAbs}[40,55,56]$ (Figure 1 ). Hence, $\mathrm{mAb}$ binding to the CD4bs enhances antigenicity of epitopes in the V3 loop. MAbs to the V2 loop also enhance antigenicity of V3, whereas mAbs to C2 have little effect on V3 [40]. These results are in agreement with an earlier study conducted with a different panel of $\mathrm{mAbs}$ [57], demonstrating the ability of selected anti-gp120 mAbs to modulate the exposure and stability of particular gp120 epitopes for better Ab recognition. These modulatory effects are determined by the fine specificity of the mAbs, indicative of Fab-mediated activity. Nevertheless, the capacity of Fab fragments, as compared to intact IgG, to enhance antigenicity of the specific epitopes has not been directly tested.

\section{gp120-Mab Complex Vaccines to Elicit HIV-Neutraliz- ing Abs}

As immune complexes made with gp120 and anti-CD4-binding site mAbs display enhanced $\mathrm{V} 3$ reactivity with cross-reactive neutralizing anti-V3 mAbs such as $447-52 \mathrm{D}$, we tested these complexes as vaccines in mice for their capacity to elicit Abs against neutralizing V3 epitopes. In multiple experiments, the immune complexes consistently elicited higher titers of serum Abs to gp120 and V3 as compared to gp120 alone or gp120 mixed with a control irrelevant $\mathrm{mAb}[40,56]$. Induction of
Ab response was also faster in immune complex-immunized animals. High titers of anti-gp120 and anti-V3 Abs were generated after two injections of the immune complex, while uncomplexed gp120 elicited detectable anti- gp120 Ab response but only after three injections; similarly, it failed to stimulate any anti-V3 Abs even after four injections [56]. Importantly, the $\mathrm{Ab}$ response induced by the complexes had potent virus-neutralizing activities (Figure 2) which, as shown in peptide blocking experiments, were mediated to a significant extent by anti-V3 Abs [40,56]. Abs to the CD4-binding site was not induced, as the site was blocked by the mAbs used to form the complexes [56]. In contrast, uncomplexed gp120 administered on its own with the same immunization method or with a DNA priming/protein boost regimen did not stimulate any detectable neutralizing $\mathrm{Abs}\left(\mathrm{IC}_{50}\right.$ titers of $\left.<50\right)$ (Figure 2 and $[40,55]$ ). We also noted that both IgG1 and IgA specific for gp120 were generated by the complexes, while the uncomplexed gp120 failed to elicit any IgA response [56]. Epitope mapping further showed that the enhanced $\mathrm{Ab}$ response was specifically directed to $\mathrm{V} 3$ [56]. Immune complexes made with two different anti-CD4bs mAbs (654-D or 559/64-D) elicited comparably high titers of anti-V3 Abs, whereas complexes made with anti-V3 or anti-C2 mAbs did not ([56] and unpublished data). When the anti-CD4bs mAb 654-D was used to construct immune complexes with gp120s from two different HIV-1 strains (e.g. LAI and JRFL), the complexes induced similarly high titers of anti-V3 Abs, albeit with distinct and complementary cross-reactivity patterns [40]. These data indicate that the observed enhancement of V3 immunogenicity is not simply due to the conventional Fc-mediated activity on any gp120/mAb immune complexes; rather, they are associated with immune complexes formed with the anti-CD4-binding site mAbs.

It is important to point out, however, that Fc-mediated activities of our gp120/Ab complex vaccines might not have been exploited to their full potential, since human mAbs (IgG1) were used to form the complexes, and immunization experiments were done in mice. The association constant of human IgG1 Fc for mouse splenic macrophages

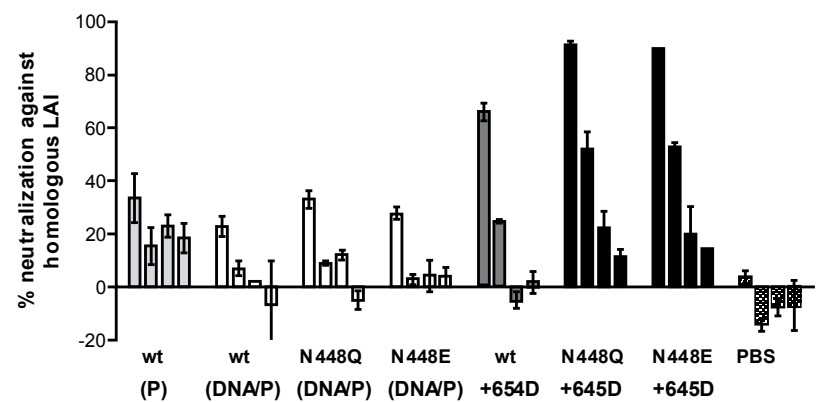

Figure 2: Neutralizing antibody response elicited by uncomplexed gp120 versus gp120/mAb complexes

Mice were immunized with wild type gp120 (wt) or immune complexes containing wild type gp120 $(\mathrm{wt}$ ) and anti-CD4-binding site mAb 654-D. Immunization was performed by intraperitoneal injections, 3 times at 2-week intervals, with MPL/DDA adjuvant [55]. Immune complexes made of mutant gp120 (N448Q or $\mathrm{N} 448 \mathrm{E}$ ) and mAb 654-D were also tested [55]. In addition, three groups of mice received intramuscular injections of DNA plasmids encoding wild type or mutant gp120 followed with subcutaneous boosts with the corresponding gp120 proteins in QS21 adjuvant (DNA/P) [55]. Two weeks after the last immunization, serum neutralizing activities were measured against pseudotyped HIV-1 bearing the homologous LAI Env in TZM-bl target cells. The bars in each group represent data from serum serially diluted three fold starting from 1:50. Means and standard deviations from duplicate wells are shown. 
is lower than that to human peripheral monocytes. Different binding modes were also reported for human IgG1 Fc binding to mouse vs. human Fc receptors expressed on mononuclear cells [58,59]. Hence, future studies should include experiments in transgenic mice expressing human FcRs or non-human primates to fully access the capacity of gp120/mAb complex vaccines to augment $\mathrm{Ab}$ responses to V3 and other critical epitopes on gp120.

\section{Improving Potency and Breadth of Neutralizing Anti- bodies Elicited by gp120/mAb Complexes}

N-linked glycans shielding most of surface gp120 modulate the exposure of critical neutralizing epitopes on this antigen, and removal of specific $\mathrm{N}$-linked glycans increases virus susceptibility to neutralizing antibodies against different epitopes [7,8,12-16]. Immunization with Env mutant lacking a glycan in the stem of V2 loop results in higher and broader serum neutralizing $\mathrm{Ab}$ responses than that with wild type Env, indicating that more effective Env immunogens may be generated by removal of select N-glycan(s) [13]. Our studies identified a glycan associated with Asn at position 448 (N448) in the C4 region of gp120 that plays a role in modulating the processing and presentation of nearby T helper epitopes $[60,61]$. Interestingly, removal of this glycan also improves $\mathrm{V} 3$ reactivity with a broadly neutralizing $\mathrm{mAb}$, without affecting other $\mathrm{Ab}$ epitopes or $\mathrm{CD} 4$-binding. When immune complexes containing gp120 mutants (N448Q or N448E) and the anti-CD4binding site $\mathrm{mAb}$ 654-D were used for immunizing mice, significantly higher titers of neutralizing $\mathrm{Ab}$ responses were elicited as compared to those raised by the wild type gp120/654-D complex (Figure 1) [55]. Peptide blocking experiments showed that neutralization was mediated in part by anti-V3 Abs, but Abs against undefined epitopes also played a role [55]. The mutated gp120 proteins alone administered by DNA priming/protein boost were unable to elicit neutralizing $\mathrm{Abs}\left(\mathrm{IC}_{50}\right.$ titers of $<50$ [55], indicating that enhanced $\mathrm{V} 3$ antigenicity (i.e. in vitro $\mathrm{Ab}$ reactivity) of the gp120 mutants is not sufficient for improving V3 immunogenicity in vivo and other important factors exist that govern epitope immunogenicity (discussed in the next section).

Our initial studies were performed with immune complexes made

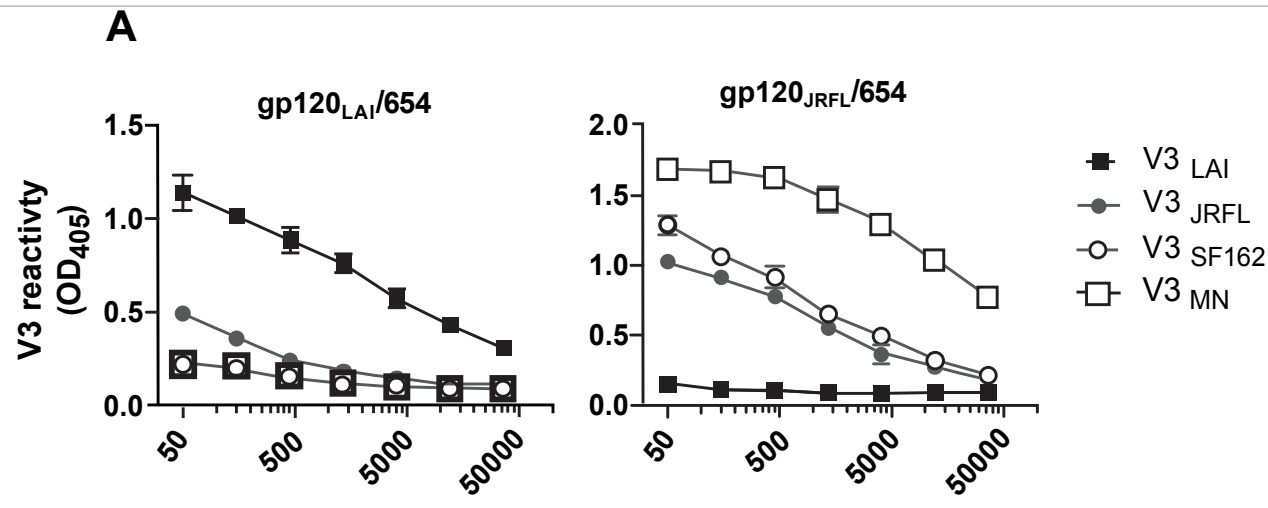

V3 Con sB : CTRPNNNTRKSI HI --GPGRAFYTTGEI IGDIRQAHC

V3 LAI : CTRPNNNTRKRI RI QRGPGRAFVTI GKI -GNMRQAHC

V3 JRFL : CTRPNNNTRKS I HI --GPGRAFYTTGEI I GDI RQAHC

V3 MN : CTRPNYNKRKRI HI --GPGRAFYTTKNI KGT I RQAHC

V3 SF 162 : CTRPNNNTRKS I TI --GPGRAFYATGDI IGDI RQAHC

\section{B}
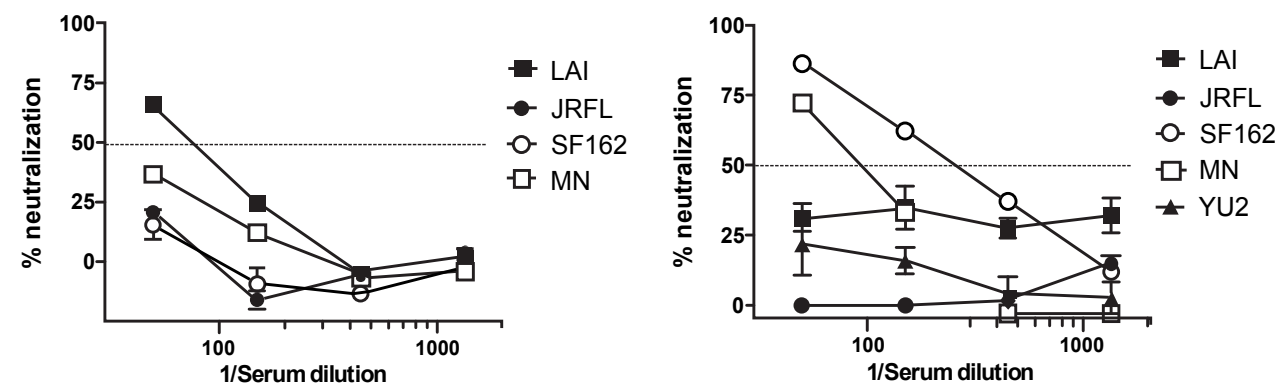

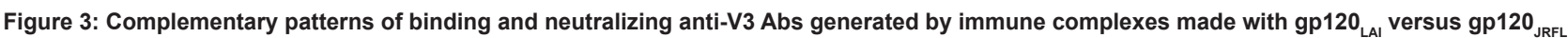

Mice were immunized with gp120 ${ }_{\mathrm{LAl}}$ or gp120 ${ }_{\mathrm{JRF}}$ complexed with mAb 654-D in the presence of MPL/DDA adjuvant. Sera collected at two weeks after the last immunization was serially diluted and tested in ELISA for reactivity with different $\mathrm{V} 3$ peptides $(\mathrm{A})$. Means and standard deviations of OD $\mathrm{D}_{\text {ins }}$ values from duplicate wells are shown. The mean $\mathrm{OD}_{405}$ values for mice immunized with uncomplexed gp120s were all $<0.5$ (data not shown) [40,55]. Amino acid sequences of $\mathrm{V} 3$, and $\mathrm{V} 3$ of consensus $B$ and other subtype $B$ isolates are shown below the graphs, with red letters marking differences between $V 3_{\text {LAI }}$ and the other $V 3$ sequences. The same sera were also tested in neutralization assays with TZM.bl cells (B). Neutralization of pseudovirus bearing different Env by immune sera. Means and standard deviation from two independent experiments are shown. Dotted lines indicate the $50 \%$ cut off for positive/negative neutralization. 


\begin{tabular}{|c|c|c|c|c|}
\hline Immunogen & $\begin{array}{c}\text { Neutralizing } \\
\text { Ab activity }^{\mathbf{a}}\end{array}$ & Antigenicity $^{\mathbf{b}}$ & $\begin{array}{c}\text { Proteolytic }_{\text {degradation }^{\mathbf{c}}} \\
\text { degral }^{\text {Helper T cell }} \\
\text { response }^{\mathbf{d}}\end{array}$ \\
\hline $\mathrm{N} 448 \mathrm{Q}$ & - & + & + & ++ \\
\hline $\mathrm{wt} / 654-\mathrm{D}$ & - & ++ & ++ & +++ \\
\hline $\mathrm{N} 448 \mathrm{Q} / 654-\mathrm{D}$ & + & ++ & ++ & + \\
\hline
\end{tabular}

aNeutralizing $\mathrm{Ab}$ activity against the homologous LAI virus was determined based on reduction of virus infection by immune sera at 1:50 dilution in standard TZM-bl assays. (-) 0-50\%; (+) 50-75\%; (++) 75-100\% [55,56].

${ }^{b} \mathrm{~V} 3$ antigenicity on the respective immunogens based on recognition by neutralizing anti-V3 mAbs $[55,56]$

${ }^{\mathrm{c}}$ Relative sensitivity of $\mathrm{V} 3$ epitopes to cathepsin L digestion [55]

${ }^{d}$ gp120-specific T cell proliferative responses of immunized animals measured in ${ }^{3} \mathrm{H}$-thymidine incorporation assays $[55,66]$.

Table 1: Immunological parameters of $\mathrm{V} 3$ epitopes presented on wild type or mutant gp120 on its own or as immune complexes with mAb 654-D.

of gp $120_{\text {LAI }}$. The $\mathrm{V} 3$ sequence of gp $120_{\text {LAI }}$ is unusual, even among subtype $B$ viruses, as it has a two amino acid insertion at the arch or tip of the $V 3$ crown and multiple non-conserved substitutions and a single deletion at both flanking sides (Figure 2). Predictably, the binding and neutralizing activities of anti-V3 Abs generated by wild type gp $120_{\text {LAI }} / 654-\mathrm{D}$ and mutant gp $120_{\mathrm{LAI}} / 654-\mathrm{D}$ complexes were highly restricted for the homologous virus (Figure 2) [55]. A more representative subtype B gp120 was tested as an immunogen for potential capacity to generate binding and neutralizing Abs that are more reactive to a larger array of subtype B viruses. V3 of gp $120_{\text {JRFL }}$ is identical to that of the subtype B consensus and gp120 $0_{\text {IRFL }}$ sequence has $91 \%$ similarity with consensus B gp120. Immunization with gp120 $0_{\text {IRFL }} / 654-D$ generated more crossreactive anti-V3 Abs recognizing both homologous and heterologous $\mathrm{V} 3$ peptides (Figure $3 \mathrm{~A}$ ). The Abs also had neutralizing activities against heterologous Tier 1 viruses known to be highly sensitive to anti-V3 Abs (SF162, MN, SS1196.1 and 3988.25) (Figure 3B and [40]). Interestingly, the Abs failed to bind to $\mathrm{V} 3_{\mathrm{LAI}}$ peptide and did not neutralize LAI virus, demonstrating complementary binding and neutralizing patterns of Abs generated by gp120 1 LAI $/ 654-\mathrm{D}$ and gp120 ${ }_{\mathrm{IRFL}} / 654-\mathrm{D}$ complexes. Nevertheless, although anti-V3 Ab response elicited by the gp120 $0_{\text {IRFL }} / 654-\mathrm{D}$ complex was reactive with the homologous V3 $3_{\text {IRFL }}$ peptide, the Abs was not able to neutralize JRFL virus. The Abs also were ineffective against other Tier 2 viruses such as YU-2 (Figure 3B), which are known to be relatively resistant to neutralization by anti-V3 Abs [62]. These data indicate that induction of Abs against other epitopes would be needed to target these V3-resistant viruses. As mAb binding to gp120 also modulates antigenicity of cross-reactive neutralizing epitopes in the CD4-binding site and the chemokine receptor binding sites outside V3 [57], additional new novel gp120/mAb complexes may be constructed to induce and skew Ab responses toward these epitopes. Currently, our lab aims to identify gp120/mAb complexes with enhanced antigenicity of epitopes in the CD4-binding sites and in the V1V2/V3 loops, and investigate their immunogenic properties following immunization. Moreover, there is renewed interest in the ability of Abs to mediate other non-neutralizing anti-viral functions and future studies will explore the capacity of Abs elicited by immune complex vaccines to contribute to ADCC, ADCVI, C'-mediated virus lysis, and other activities beyond virus neutralization.

\section{Immunological Parameters that Contribute to En- hanced Immunogenicity of gp 120/m Ab Complexes}

To further improve the immunogenicity of epitopes that HIV vaccines and to design more effective immunogens presenting these epitopes, a better understanding of factors governing epitope immunogenicity is needed. From our recent efforts to augment V3 immunogenicity by a combination of immune complex vaccine strategy and N-glycan removal, immunological parameters that do and do not correlate with enhanced immunogenicity are revealed (Table 1).

\section{In vitro antigenicity}

As described, mAb binding to gp120 alters gp120 conformation that affects exposure and reactivity of epitopes on this antigen. Indeed, immune complexes of gp120 and anti-CD4-binding site mAb 654-D that elicited anti-V3 Abs displayed enhanced V3 antigenicity as demonstrated by significantly higher reactivity of anti-V3 mAbs to the complexes than to uncomplexed gp120 (Table 1) [40,55]. Further increase in V3 antigenicity was observed with N448Q gp120 mutant complexed with the same $\mathrm{mAb}$, resulting in induction of more elevated titers of neutralizing Abs than achieved by the wild type complex. These data indicate a direct correlation between V3 immunogenicity in vivo and in vitro antigenicity. However, antigenicity is not the only parameter influencing immunogenicity. Antigenicity of an epitope in the N-terminal C1 region, like V3, was also enhanced when presented on gp120/mAb 654-D complexes, but in vivo $\mathrm{Ab}$ response to $\mathrm{C} 1$ was unaltered $[40,56]$. Similarly, as mentioned and shown in Table 1, V3 epitopes were better recognized on N448Q gp120 than on wild type gp120, but this enhancement was not sufficient for the mutant gp120 on its own to induce anti-V3 Ab response. These data suggest that epitope immunogenicity is not governed only by its antigenicity and that assessment of candidate vaccine immunogens should go beyond measurement of antigenicity alone.

\section{Sensitivity to proteolytic degradation}

Increased exposure of $\mathrm{V} 3$ that leads to its better recognition by Abs may also render $\mathrm{V} 3$ epitopes more accessible and sensitive to degradative enzymes. Yu et al. [63] identified that many proteolytic cleavage sites on gp120 recognized by endolysosomal proteases important for antigen processing and presentation cluster in conserved regions associated with receptor binding sites and cross-reactive neutralizing epitopes including V3. Proteolytic degradation of the epitopes would prevent generation of $\mathrm{Ab}$ response against conformation-dependent epitopes recognized by most virus-neutralizing Abs. Our studies show that although V3 antigenicity was augmented by N448-glycan removal, the mutation also rendered V3 epitopes more susceptible to cathepsin L and the mutant protein was not able to induce anti-V3 Abs on its own (Table 1). However, when complexed with the anti-CD4-binding site $\mathrm{mAb} 654-\mathrm{D}$, it potently stimulated neutralizing anti- $\mathrm{V} 3 \mathrm{Ab}$ response to titers higher than those attained by the wild type gp120/654-D complex. Interestingly, V3 epitopes on the mutant gp120/654-D complex were not only most antigenic (i.e. best recognized by anti-V3 mAbs) but also most resistant to proteolysis. This is consistent with earlier findings in our lab and others $[52,64]$ that demonstrate the capacity of anti-CD4binding site mAbs, similar to CD4, to stabilize gp120 and increase its resistance against degradation by proteases and endoglycosidases as a result of substantial thermodynamic changes induced by mAb binding to gp120 [51]. Collectively, these data indicate that improvement of V3 immunogenicity can be achieved by augmenting both antigenicity and proteolytic resistance. Whether the same principles govern immunogenicity of other epitopes on the viral Env remain to be determined, but they provide rational testable strategies in designing novel immunogens to present specific Ab epitopes that vaccines aim to target. 


\begin{tabular}{|c|c|}
\hline Potency & Breadth \\
\hline $\begin{array}{c}\text { Immune complexes constructed } \\
\text { with gp120 mutants lacking specific } \\
\mathrm{N} \text { - glycans to better expose targeted } \\
\text { epitopes }\end{array}$ & $\begin{array}{c}\text { Immune complexes formed with differ- } \\
\text { ent gp120 antigens displaying distinct } \\
\text { variants of targeted epitopes }\end{array}$ \\
\hline $\begin{array}{c}\text { Adjuvants targeting different TLRs or } \\
\text { other pathogen recognition receptors }\end{array}$ & $\begin{array}{c}\text { Immune complexes formed with differ- } \\
\text { ent mAbs to enhance immunogencity of } \\
\text { different epitopes targeted on gp120 }\end{array}$ \\
$\begin{array}{c}\text { Use of gp120/mAb complexes as } \\
\text { boosting immunogens following priming } \\
\text { with DNA or other vectors }\end{array}$ & $\begin{array}{c}\text { A cocktail of immune complexes to } \\
\text { target multiple different epitopes and } \\
\text { epitope variants }\end{array}$ \\
\hline
\end{tabular}

Table 2: Approaches to further improve the potency and breadth of Ab responses elicited by immune complex vaccines.

\section{Helper T cell response}

As described, Abs facilitate antigen uptake and modulate antigen processing and presentation for MHC class II-restricted helper CD4 T cells. It is of interest to point out that while gp $120 / \mathrm{mAb} 654-$ $\mathrm{D}$ complexes are potent immunogens for elicitation of neutralizing $\mathrm{Ab}$ responses, 654-D and other $\mathrm{mAbs}$ to the $\mathrm{CD} 4$-binding site have suppressive effects on MHC class II presentation of gp120 [64-66]. As Abs directed to other regions of gp 120 cause no inhibition, it is apparent that this effect is specific for anti-CD4-binding site Abs. gp120 bound by the anti-CD4-binding site $\mathrm{mAbs}$ is ingested and transported into the acidic endolysosomes of antigen presenting cells $[64,65]$. However, the complexes of gp120 and anti-CD4bs mAbs remain stable at the acidic $\mathrm{pH}$ of the endolysosomes [64] and are resistant to proteolytic digestion by endosomal enzymes $[64,65]$, such that gp120 antigen processing is obstructed and helper epitope peptides are not efficiently generated and presented on MHC class II to CD4 T cells. The mAbs do not have negative effects on the $\mathrm{T}$ cell themselves, as the $\mathrm{T}$ cell response to synthetic peptides representing already processed gp120 epitopes is not affected by the anti-CD4bs mAbs [67]. T cells specific for other antigens, such as HIV-1 gag p24, Mycobacterium tuberculosis antigens, cytomegalovirus, are also not affected by the mAbs or the immune complexes [67]. Notably, the obstructive effect of the anti-CD4bs mAbs on gp120 antigen processing is not simply due to steric hindrance of a particular helper epitope by the mAbs. These mAbs inhibit the processing and presentation of helper epitopes in the $\mathrm{C} 1, \mathrm{C} 2, \mathrm{~V} 2$, or V3 regions distant from the CD4 binding site [56,65,67], indicative of their global effects. In support of these in vitro data, immunization of mice with the gp120/mAb 654-D complex resulted in a lower level of gp120-specific lymphoproliferation than that with uncomplexed gp120 or a different complex made with an anti-C5 mAb [66]. Reduced proliferation was also seen in response to multiple overlapping peptides spanning the entire gp120, indicating that the mAb suppresses CD4 $\mathrm{T}$ cell responses to various epitopes on gp120. Hence, $\mathrm{Ab}$ binding to the CD4-binding site of gp120 modulates CD4 T cell and Ab responses to gp120 in disparate ways. In contrast, the N448Q mutation has enhancing effects on CD4 T cell response, but the protein alone does not elicit neutralizing Abs and only immunization with the N448Q/654-D complex elicits high titers of neutralizing Abs. Enhanced $\mathrm{Ab}$ response induced by these immune complexes occurs in the absence of optimal helper CD4 T cell response to gp120, and this opens another venue to exploit for improving this vaccine strategy (Table 2). New adjuvants incorporating multiple TLR ligands such as TLR-9 ligand CpG-ODN and TLR7/8 ligand resiquimod (R848) may be utilized in order to elicit both $\mathrm{B}$ cell and $\mathrm{T}$ cell responses $[68,69]$. In addition, a vaccine regimen that combines DNA or other vectors expressing gp120 to elicit T cells and the gp120/654-D complex to stimulate Abs is currently being investigated for the capacity to generate a balanced immune response that confers more potent and durable anti-viral immunity.

\section{Conclusion}

To prevent infection of a large array of circulating HIV-1 isolates, $\mathrm{HIV}$ vaccines need to induce high titers of $\mathrm{Ab}$ responses that simultaneously target multiple critical epitopes on the virus Env and multiple variants within each of the epitopes. Using V3 as a prototype, we demonstrated the utilization of immune complex vaccine strategy to augment V3 immunogenicity. We provide evidence that immune complex vaccines are capable of inducing high titers of neutralizing $\mathrm{Ab}$ responses directed to $\mathrm{V} 3$. Induction of neutralizing Abs specific for distinct V3 variants is also attained by immunization with immune complexes made of different gp120 proteins. Current efforts are aimed to tackle the challenge whether the immune complex vaccines may also be exploited for eliciting high titers of $\mathrm{Ab}$ responses against potent neutralizing epitopes in the CD4-binding site and/or recently identified epitopes involving $\mathrm{N}$-linked glycans and other conserved elements in the V1, V2, and V3 loops (Table 2). We envision that a vaccine may be developed that will incorporate multiple immune complexes to target the different epitopes and their distinct variants, and that such complexes will ultimately be combined with DNA or other vectors to stimulate balanced antibody and $\mathrm{T}$ cell responses that confer durable immunity against HIV.

\section{References}

1. Flynn NM, Forthal DN, Harro CD, Judson FN, Mayer KH, et al. (2005) Placebocontrolled phase 3 trial of a recombinant glycoprotein 120 vaccine to prevent HIV-1 infection. J Infect Dis 191: 654-665.

2. Pitisuttithum P, Gilbert P, Gurwith M, Heyward W, Martin M, et al. (2006) Randomized, double-blind, placebo-controlled efficacy trial of a bivalent recombinant glycoprotein $120 \mathrm{HIV}-1$ vaccine among injection drug users in Bangkok, Thailand. J Infect Dis 194: 1661-1671.

3. Gray G, Buchbinder S, Duerr A (2010) Overview of STEP and Phambili trial results: two phase Ilb test-of-concept studies investigating the efficacy of MRK adenovirus type $5 \mathrm{gag} / \mathrm{pol} / \mathrm{nef}$ subtype B HIV vaccine. Curr Opin HIV AIDS 5: 357-361.

4. Rerks-Ngarm S, Pitisuttithum P, Nitayaphan S, Kaewkungwal J, Chiu J, et al (2009) Vaccination with ALVAC and AIDSVAX to prevent HIV-1 infection in Thailand. N Engl J Med 361: 2209-2220.

5. Zolla-Pazner S (2004) Identifying epitopes of HIV-1 that induce protective antibodies. Nat Rev Immunol 4: 199-210.

6. Burton DR, Desrosiers RC, Doms RW, Koff WC, Kwong PD, et al. (2004) HIV vaccine design and the neutralizing antibody problem. Nat Immunol 5: 233-236.

7. Reitter JN, Means RE, Desrosiers RC (1998) A role for carbohydrates in immune evasion in AIDS. Nat Med 4: 679-684.

8. McCaffrey RA, Saunders C, Hensel M, Stamatatos L (2004) N-linked glycosylation of the V3 loop and the immunologically silent face of gp120 protects human immunodeficiency virus type1 SF162 from neutralization by anti-gp120 and anti-gp41 antibodies. J Virol 78: 3279-3295.

9. LyA, Stamatatos $L(2000)$ V2 loop glycosylation of the human immunodeficiency virus type 1 SF162 envelope facilitates interaction of this protein with CD4 and CCR5 receptors and protects the virus from neutralization by anti-V3 loop and anti-CD4 binding site antibodies. J Virol 74: 6769-6776.

10. Wolk T, Schreiber M (2006) N-Glycans in the gp120 V1/V2 domain of the HIV1 strain NL4-3 are indispensable for viral infectivity and resistance against antibody neutralization. Med Microbiol Immunol 195: 165-172.

11. Teeraputon S, Louisirirojchanakul S, Auewarakul P (2005) N-linked glycosylation in $\mathrm{C} 2$ region of HIV-1 envelope reduces sensitivity to neutralizing antibodies. Viral Immunol 8: 343-353.

12. Quinones-Kochs MI, Buonocore L, Rose JK (2002) Role of N-linked glycans in a human immunodeficiency virus envelope glycoprotein: effects on protein function and the neutralizing antibody response. J Virol 76: 4199-4211. 
Citation: Kumar R, Visciano ML, Li H, Hioe C (2012) Targeting a Neutralizing Epitope of HIV Envelope Gp120 by Immune Complex Vaccine. J AIDS Clinic Res S8:002. doi:10.4172/2155-6113.S8-002

13. Li Y, Cleveland B, Klots I, Travis B, Richardson BA, et al. (2008) Removal of a single $\mathrm{N}$-linked glycan in human immunodeficiency virus type $1 \mathrm{gp} 120$ results in an enhanced ability to induce neutralizing antibody responses. J Virol 82 638-651.

14. Reitter JN, Desrosiers RC (1998) Identification of replication-competent strains of simian immunodeficiency virus lacking multiple attachment sites for $\mathrm{N}$-linked carbohydrates in variable regions 1 and 2 of the surface envelope protein. J Virol 72: 5399-5407.

15. Reynard F, Fatmi A, Verrier B, Bedin F (2004) HIV-1 acute infection env glycomutants designed from 3D model: effects on processing, antigenicity, and neutralization sensitivity. Virology 324: 90-102.

16. Wu Z, Kayman SC, Honnen W, Revesz K, Chen H, et al. (1995) Characterization of neutralization epitopes in the $\mathrm{V} 2$ region of human immunodeficiency virus type $1 \mathrm{gp} 120$ : role of glycosylation in the correct folding of the V1/V2 domain. J Virol 69: 2271-2278.

17. Kwong PD, Doyle ML, Casper DJ, Cicala C, Leavitt SA, et al. (2002) HIV-1 evades antibody-mediated neutralization through conformational masking of receptor-binding sites. Nature 420: 678-682.

18. Li B, Decker JM, Johnson RW, Bibollet-Ruche F, Wei X, et al. (2006) Evidence for potent autologous neutralizing antibody titers and compact envelopes in early infection with subtype $\mathrm{C}$ human immunodeficiency virus type1. J Virol 80: 5211-5218.

19. Richman DD, Wrin T, Little SJ, Petropoulos CJ (2003) Rapid evolution of the neutralizing antibody response to HIV type 1 infection. Proc Natl Acad Sci U S A 100: 4144-4149.

20. Sather DN, Armann J, Ching LK, Mavrantoni A, Sellhorn G, et al. (2009) Factors associated with the development of cross-reactive neutralizing antibodies during human immunodeficiency virus type 1 infection. J Virol 83 : 757-769.

21. Levesque MC, Moody MA, Hwang KK, Marshall DJ, Whitesides JF, et al. (2009) Polyclonal B Cell Differentiation and Loss of Gastrointestinal Tract Germinal Centers in the Earliest Stages of HIV-1 Infection. PLoS Med 6: e1000107.

22. Zhou T, Georgiev I, Wu X, Yang ZY, Dai K, et al. (2010) Structural basis for broad and potent neutralization of HIV-1 by antibody VRC01. Science 329 : 811-817.

23. Pancera M, McLellan JS, Wu X, Zhu J, Changela A, et al. (2010) Crystal structure of PG16 and chimeric dissection with somatically related PG9: structure-function analysis of two quaternary-specific antibodies that effectively neutralize HIV-1. J Virol 84: 8098-8110.

24. Gray ES, Madiga MC, Hermanus T, Moore PL, Wibmer CK, et al. (2011) The neutralization breadth of HIV-1 develops incrementally over four years and is associated with CD4+ T cell decline and high viral load during acute infection. J Virol 85: 4828-4840.

25. Ng CT, Jaworski JP, Jayaraman P, Sutton WF, Delio P, et al. (2010) Passive neutralizing antibody controls SHIV viremia and enhances $B$ cell responses in infant macaques. Nat Med 16: 1117-1119.

26. Walker LM, Phogat SK, Chan-Hui PY, Wagner D, Phung P, et al. (2009) Broad and potent neutralizing antibodies from an African donor reveal a new HIV-1 vaccine target. Science 326: 285-289.

27. Walker LM, Simek MD, Priddy F, Gach JS, Wagner D, et al. (2010) A limited number of antibody specificities mediate broad and potent serum neutralization in selected HIV-1 Infected individuals. PLoS Pathog 6: e1001028.

28. Bonsignori M, Hwang KK, Chen X, Tsao CY, Morris L, et al. (2011) Analysis of a clonal lineage of HIV-1 envelope V2/V3 conformational epitope-specific broadly neutralizing antibodies and their inferred unmutated common ancestors. J Virol 85: 9998-10009.

29. Wu X, Yang ZY, Li Y, Hogerkorp CM, Schief WR, et al. (2010) Rational design of envelope identifies broadly neutralizing human monoclonal antibodies to HIV-1. Science 329: 856-861.

30. Walker LM, Huber M, Doores KJ, Falkowska E, Pejchal R, et al. (2011) Broad neutralization coverage of HIV by multiple highly potent antibodies. Nature 477: 466-470.

31. Simek MD, Rida W, Priddy FH, Pung P, Carrow E, et al. (2009) Human immunodeficiency virus type 1 elite neutralizers: individuals with broad and potent neutralizing activity identified by using a high-throughput neutralization assay together with an analytical selection algorithm. J Virol 83: 7337-7348.
32. Li Y, Svehla K, Louder MK, Wycuff D, Phogat S, et al. (2009) Analysis of neutralization specificities in polyclonal sera derived from human immunodeficiency virus type 1-infected individuals. J Virol 83: 1045-1059.

33. Heyman B (2000) Regulation of antibody responses via antibodies, complement, and Fc receptors. Annu Rev Immunol 18: 709-737.

34. McCluskie MJ, Wen YM, Di Q, Davis HL (1998) Immunization against hepatitis $B$ virus by mucosal administration of antigen-antibody complexes. Viral Immunol 11: 245-252

35. Wen YM, Qu D, Zhou SH (1999) Antigen-antibody complex as therapeutic vaccine for viral hepatitis B. Int Rev Immunol 18: 251-258.

36. Ivan J, Velhner M, Ursu K, German P, Mato T, et al. (2005) Delayed vaccine virus replication in chickens vaccinated subcutaneously with an immune complex infectious bursal disease vaccine: quantification of vaccine virus by real-time polymerase chain reaction. Can J Vet Res 69: 135-142.

37. Alber DG, Killington RA, Stokes A (2000) Solid matrix-antibody-antigen complexes incorporating equine herpesvirus 1 glycoproteins $C$ and $D$ elicit anti-viral immune responses in $\mathrm{BALB} / \mathrm{c}(\mathrm{H}-2 \mathrm{~K}(\mathrm{~d}))$ and $\mathrm{C} 3 \mathrm{H}(\mathrm{H}-2 \mathrm{~K}(\mathrm{k}))$ mice. Vaccine 19: 895-901.

38. Roic B, Cajavec S, Ergotic N, Lipej Z, Madic J, et al. (2006) Immune complexbased vaccine for pig protection against parvovirus. J Vet Med B Infect Dis Vet Public Health 53: 17-23.

39. Rawool DB, Bitsaktsis C, Li Y, Gosselin DR, Lin Y, et al. (2008) Utilization of Fc receptors as a mucosal vaccine strategy against an intracellular bacterium, Francisella tularensis. J Immunol 180: 5548-5557.

40. Hioe CE, Visciano ML, Kumar R, Liu J, Mack EA, et al. (2009) The use of immune complex vaccines to enhance antibody responses against neutralizing epitopes on HIV-1 envelope gp120. Vaccine 28: 352-360.

41. Getahun A, Heyman B (2006) How antibodies act as natural adjuvants Immunol Lett 104: 38-45.

42. Heyman B (1990) The immune complex: possible ways of regulating the antibody response. Immunol Today 11: 310-313.

43. Jemmerson R, Paterson $Y$ (1986) Mapping epitopes on a protein antigen by the proteolysis of antigen-antibody complexes. Science 232: 1001-1004.

44. Brady LJ, van Tilburg ML, Alford CE, McArthur WP (2000) Monoclona antibody-mediated modulation of the humoral immune response against mucosally applied Streptococcus mutans. Infect Immun 68: 1796-1805.

45. Oli MW, Rhodin N, McArthur WP, Brady LJ (2004) Redirecting the humora immune response against Streptococcus mutans antigen P1 with monoclonal antibodies. Infect Immun 72: 6951-6960.

46. Bouige P, Iscaki S, Cosson A, Pillot J (1996) Molecular analysis of the modulatory factors of the response to HBsAg in mice as an approach to HBV vaccine enhancement. FEMS Immunol Med Microbiol 13: 71-79.

47. Denisova G, Stern B, Raviv D, Zwickel J, Smorodinsky NI, et al. (1996) Humoral immune response to immunocomplexed HIV envelope glycoprotein 120. AIDS Res Hum Retroviruses 12: 901-909.

48. Bowman J, Harman C, Manning F, Menticoglou S, Pollock J (1991) Intravenous drug abuse causes Rh immunization. Vox Sang 61: 96-98.

49. Karlsson MC, Wernersson S, Diaz de Stahl T, Gustavsson S, Heyman B (1999) Efficient IgG- mediated suppression of primary antibody responses in Fcgamma receptor-deficient mice. Proc Natl Acad Sci U S A 96: 2244-2249.

50. Quintana IZ, Silveira AV, Moller G (1987) Regulation of the antibody response to sheep erythrocytes by monoclonal IgG antibodies. Eur J Immunol 17: 13431349 .

51. Myszka DG, Sweet RW, Hensley P, Brigham-Burke M, Kwong PD, et al. (2000) Energetics of the HIV gp120-CD4 binding reaction. Proc Natl Acad Sci U S A 97: 9026-9031.

52. Kwong PD, Wyatt R, Robinson J, Sweet RW, Sodroski J, et al. (1998) Structure of an HIV gp120 envelope glycoprotein in complex with the CD4 receptor and a neutralizing human antibody. Nature 393: 648-659.

53. Chen B, Vogan EM, Gong H, Skehel JJ, Wiley DC, et al. (2005) Structure of an unliganded simian immunodeficiency virus gp120 core. Nature 433: 834-841.

54. Liao HX, Alam SM, Mascola JR, Robinson J, Ma B, et al. (2004) Immunogenicity of constrained monoclonal antibody A32-human immunodeficiency virus (HIV) 
Citation: Kumar R, Visciano ML, Li H, Hioe C (2012) Targeting a Neutralizing Epitope of HIV Envelope Gp120 by Immune Complex Vaccine. J AIDS Clinic Res S8:002. doi:10.4172/2155-6113.S8-002

Env gp120 complexes compared to that of recombinant HIV type $1 \mathrm{gp} 120$ envelope glycoproteins. J Virol 78: 5270-5278.

55. Kumar R, Tuen M, Li H, Tse DB, Hioe CE (2011) Improving immunogenicity of HIV-1 envelope gp120 by glycan removal and immune complex formation. Vaccine 29: 9064-9074.

56. Visciano ML, Tuen M, Gorny MK, Hioe CE (2008) In vivo alteration of humoral responses to HIV-1 envelope glycoprotein gp120 by antibodies to the CD4binding site of gp120. Virology 372: 409-420.

57. Moore JP, Sodroski J (1996) Antibody cross-competition analysis of the human immunodeficiency virus type1 gp120 exterior envelope glycoprotein J Virol 70: 1863-1872.

58. Ratcliffe A, Stanworth DR (1982) The use of synthetic gamma-chain peptides in the localization of the binding site(s) on human lgG1 for the Fc receptors of homologous monocytes and heterologous mouse macrophages. Immunol Lett 4: 215-221.

59. Ratcliffe A, Stanworth DR (1983) The localization of the binding site(s) on human IgG1 for the Fc receptors on homologous monocytes and heterologous mouse macrophages. Immunology 50: 93-100.

60. Li H, Chien PC Jr, Tuen M, Visciano ML, Cohen S, et al. (2008) Identification of an $\mathrm{N}$ - linked glycosylation in the $\mathrm{C} 4$ region of HIV-1 envelope gp120 that is critical for recognition of neighboring CD4 T cell epitopes. J Immunol 180: 4011-4021.

61. Li H, Xu CF, Blais S, Wan Q, Zhang HT, et al. (2009) Proximal glycans outside of the epitopes regulate the presentation of HIV-1 envelope gp120 helper epitopes. J Immunol 182: 6369-6378.

62. Hioe CE, Wrin T, Seaman MS, Yu X, Wood B, et al. (2010) Anti-V3 monoclonal antibodies display broad neutralizing activities against multiple HIV-1 subtypes. PLoS One 5: e10254.

63. Yu B, Fonseca DP, O'Rourke SM, Berman PW (2010) Protease cleavage sites in HIV-1 gp120 recognized by antigen processing enzymes are conserved and located at receptor binding sites. J Virol 84: 1513-1526.
64. Tuen M, Visciano ML, Chien PC Jr, Cohen S, Chen PD, et al. (2005) Characterization of antibodies that inhibit HIV gp120 antigen processing and presentation. Eur J Immunol 35: 2541-2551.

65. Chien PC Jr, Cohen S, Tuen M, Arthos J, Chen PD, et al. (2004) Human immunodeficiency virus type 1 evades T-helper responses by exploiting antibodies that suppress antigen processing. J Virol 78: 7645-7652.

66. Visciano ML, Tuen M, Chen PD, Hioe CE (2008) Antibodies to the CD4binding site of HIV-1 gp120 suppress gp120-specific CD4 T cell response while enhancing antibody response. Infect Agent Cancer 3: 11.

67. Hioe CE, Jones GJ, Rees AD, Ratto-Kim S, Birx D, et al. (2000) Anti-CD4 binding domain antibodies complexed with HIV type 1 glycoprotein 120 inhibit CD4+ T cell-proliferative responses to glycoprotein 120. AIDS Res Hum Retroviruses 16: 893-905.

68. Kwissa M, Nakaya HI, Oluoch H, Pulendran B (2012) Distinct TLR adjuvants differentially stimulate systemic and local innate immune responses in nonhuman primates. Blood 119: 2044-2055.

69. Tacken PJ, Zeelenberg IS, Cruz LJ, van Hout-Kuijer MA, van de Glind G, et al. (2011) Targeted delivery of TLR ligands to human and mouse dendritic cells strongly enhances adjuvanticity. Blood 118: 6836-6844.

70. Ferrari G, Pollara J, Kozink D, Harms T, Drinker M, et al. (2011) A HIV-1 gp120 Envelope Human Monoclonal Antibody that Recognizes a C1 Conformational Epitope Mediates Potent ADCC Activity and Defines a Common ADCC epitope in Human HIV-1 Serum. J Virol 85: 7029-7036.

71. Chen L, Kwon YD, Zhou T, Wu X, O'Dell S, et al. (2009) Structural basis of immune evasion at the site of CD4 attachment on HIV-1 gp120. Science 326: 1123-1127.

72. Zhou T, Xu L, Dey B, Hessell AJ, Van Ryk D, et al. (2007) Structural definition of a conserved neutralization epitope on HIV-1 gp120. Nature 445: 732-737.

73. Emileh A, Abrams CF (2011) A mechanism by which binding of the broadly neutralizing antibody b12 unfolds the inner domain alpha1 helix in an engineered HIV-1 gp120. Proteins 79: 537-546.
This article was originally published in a special issue, Vaccine research: HIV handled by Editor(s). Dr. Marc Van Regenmortel, University of Strasbourg, France 